\title{
A Future Journey to the Elderly Support in Bangladesh
}

\author{
M. Nazrul Islam ${ }^{1}$ and Dilip C. Nath ${ }^{2}$ \\ ${ }^{1}$ Department of Statistics, Shahjalal University of Science and Technology, Sylhet 3114, Bangladesh \\ ${ }^{2}$ Department of Statistics, Gauhati University, Assam, Guwahati 781014, India
}

Correspondence should be addressed to M. Nazrul Islam, nazrul330@yahoo.com

Received 28 March 2012; Accepted 14 May 2012

Academic Editor: Santos Alonso

Copyright (C 2012 M. N. Islam and D. C. Nath. This is an open access article distributed under the Creative Commons Attribution License, which permits unrestricted use, distribution, and reproduction in any medium, provided the original work is properly cited.

Bangladesh is not an exception from the global phenomenon of demographic aging. It is a relatively new issue in the country as its demographic transition started recently. An important issue on aging study is the support facility to the elderly. The support system to the elderly is gradually decreasing in this country though the burden does not reach the alarming situation. This paper tries to show the future path of demographic support capacity for the elderly based on secondary (1981-2001) and projected (2011-2071) data. The study shows a future gloomy picture of the elderly support facility in terms of both economic and caring aspects. This dimension of future inevitable aging problem needs proper attention to the policy makers for taking sustainable aging policies. Introduction of this agenda to the nation's five-year planning will be effective to face the problem phase by phase.

\section{Introduction}

Global population aging is a by-product of the demographic transition in which both mortality and fertility decline from high level to low levels. As the twentieth century drew to a close, population aging and its social and economic consequences were drawing increased attention from policy makers' worldwide. The twenty-first century will witness even more rapid population aging than did the century just past. In many cases, more rapid population aging will be taking place in countries where the level of economic development is still low [1].

The topic of the elderly support was not an issue for discussion in most of the developing countries so long ago. Only a small proportion of population lived beyond middle ages; therefore, those few that actually survived into old age were also deified, solidly entrenched into the family support system. Decline in fertility has not only increased the proportion of people surviving to the old age but has also eroded the traditional support base in old age, that is, the family. The reduction in the size of successive birth cohort not only signifies the diminishing availability of youngster to support the older people but the shrinking of family size itself [2]. Measures of societal dependency in the form of age ratios tend largely to be used as surrogates for measures of economic support even though they should be seen merely as representing the contribution of age composition of the population to the economic support problem. While the rising dependency of the aged has been more than offset by the falling dependency of the children, the economic support problem of the elderly is the greater one when one considers public support only. The age-based measures are not very good indications of the level of familial dependency and serve to provide only rough indications of its trends [3].

The changing age-sex structure of population due to demographic aging will require the change in the pattern of production as per the demands of young and old population of the country. The industries would need to respond by adjusting their production to meet the new and nascent demand [4]. Developing countries will have an old demographic profile at much lower level of socioeconomic development than the developed countries. It will have important implications for the policy makers and planners of socioeconomic development. The demand for health services and welfare measures for the elderly will increase, as the number of elderly grows. The pressure on resources and transformation of economics has also diluted the economic strength of the elderly. In association with decline in the ability and willingness of the families (under the pressure of modernization and urbanization) to support the elderly, it may further compound the problem of support provision for 
them [2]. The future number of elderly tells us something about how many hospital beds, geriatricians, home health aides, and nursing home beds will be needed. The proportion of the aged, and especially the oldest-old, tells us how many working-age adults will be available to provide financial support to the elderly and to work as home health aides, geriatricians, food services workers, and so on [5].

In Bangladesh, adult children, particularly sons, are considered to be the main source of security and economic support to their parents, particularly in the time of disaster, sickness and in old age [6]. As an Asian country, Bangladesh has a long cultural and religious tradition of looking after the elderly and it is expected that families and communities will care for their own elderly members. But rapid socioeconomic and demographic transitions, mass poverty, changing social and religious values, influence of western culture, and other factors have broken down the traditional extended family and community care system. Most of the elderly people in Bangladesh suffer from some basic human problems, such as poor financial support, senile diseases, and absence of proper health and medicine facilities, exclusion and negligence, deprivation, and socioeconomic insecurity [7].

Aging is one of the emerging problems in Bangladesh. This problem has been gradually increasing with its far reaching consequences. A macrolevel investigation on aging of Bangladesh to identify the real demographic issues has been done by [8]. They have noticed that the Bangladesh population aging tends to increase fiscal demands on the government, especially for income support, health, and social services. A clear indication of increasing Bangladesh demographic aging process has been found $[9,10]$. The elderly of Bangladesh are generally taken care of by family and society. Due to the process of globalization, this tradition support system is weakening day by day. A clear trajectory is needed to face the future support burden of the old. The paper tries to show a future roadmap of the elderly support capacity from the demographic view point.

\section{Data and Methods}

Age and gender-specific census data of Bangladesh population for the year 1981, 1991, and 2001 have been collected from the official publication of Bangladesh Bureau of Statistics [11], International Data Base (IDB), US census Bureau [12]. A medium variant population projection has been performed with Spectrum 3.2 software for 2011 to 2071 with 2001 base population. Various calculations have been done with MS Excel software. The following indices are used to measure the aging and support capacity to the elderly of the country.

2.1. Proportion of Aged Person $\left(P_{60}\right)$. It is the ratio of number of persons aged sixty or more to the total population of a country at that time. It is known as measure of aging at peak.

2.2. Proportion of Children $\left(P_{15}\right)$. It is the ratio of number of persons below fifteen to the total population of a country at that time. It is known as measure of aging at base.
2.3. Aging Index (AI). The aging index is calculated as the number of persons 60 years old or over per hundred persons under age 15. This index is considered as better measure of aging as it considers both peak and base population.

2.4. Median Age $(M d)$. The median age of a population is that age that divides a population into two groups of the same size, such as half the total population is younger than this age, and the other half older.

2.5. Young Dependency Ratio (YDR). The young dependency ratio is the number of persons 0 to 14 years per hundred persons 15 to 59 years.

2.6. Old-Age Dependency Ratio (OADR). The old-age dependency ratio is the number of persons 60 years and over per one hundred persons 15 to 59 years.

2.7. Total Dependency Ratio (DR). The total dependency ratio (DR) is the number of persons under age 15 plus aged 60 or older per one hundred persons 15-59. It is the sum of young dependency ratio (YDR) and the old-age dependency ratio (OADR).

2.8. Potential Support Ratio (PSR). The potential support ratio is the number of persons aged 15 to 59 per every person aged 60 or older.

2.9. Familial Support Ratio (FSR). Familial support ratio is the number of females aged 50-59 per 100 persons aged 60 and above. It is an important measure of elderly support system.

2.10. Elderly Support Ratio by Adult Male or Female. It is the ratio of persons aged 60 or older per 100 males or females aged between 35 and 59 years. This type of support burden of elderly was studied in India [2]. In calculating the support burden of elderly, it is believed that this support will be required when a person reaches 60 or 65 years of age. Assuming that in India the average age of childbearing is 25 years (i.e., mean age of a person when he/she has the first child particularly the son. In most societies, the eldest son is more obliged to provide care to the old age people), by the time a person attains 60 years of age, the oldest son will be 35 years old. It means that the direct support burden of elderly would be more on adults in 35-60 years age group than on all the people in working age group (15-59 years). The old age support index constructed on the basis of this information is expected to be more sensitive to the changes in population age structure.

2.11. Elderly Sex Ratio (ESR). It is the ratio of the number of male persons age 60 and over to the number female persons of this age group. 


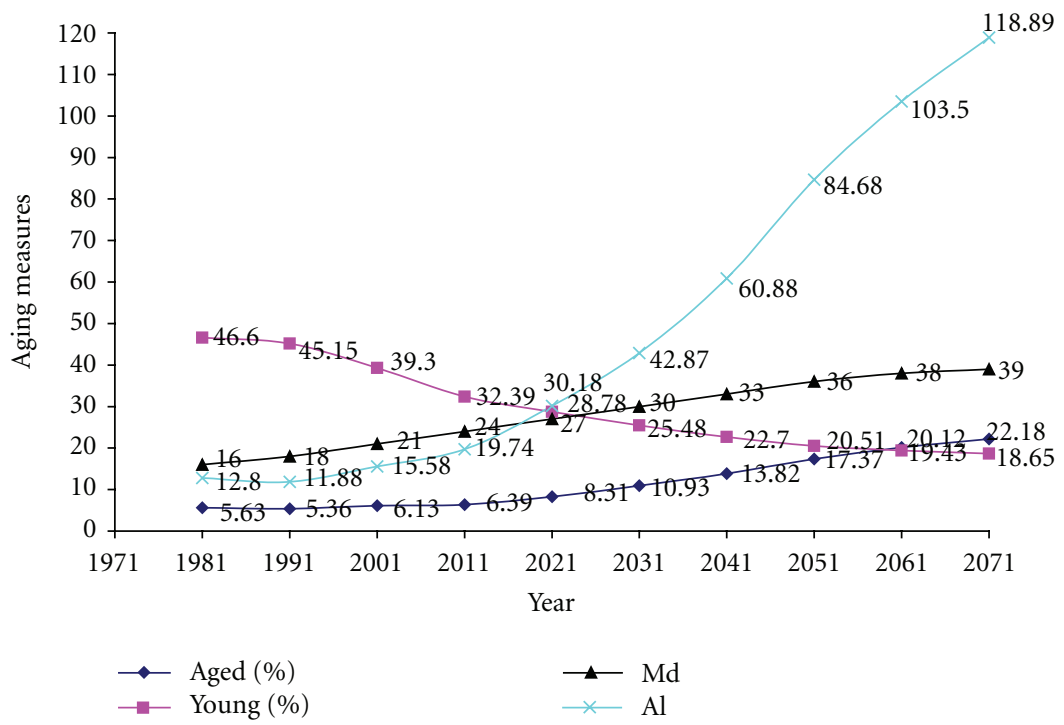

FIGURE 1: Aging measures of Bangladesh population, 1981-2071.

\section{Future Aging in Bangladesh}

Until the 20th century, Bangladesh population was young, and, at the dawn of the 21 st century, its population entered to the intermediate level of aging. The proportion of aged persons will be rising steadily up to entering the old type of population by the year 2031 and then there will be slightly sharp rising trend between 2031, and 2071 leveling the position of Japan 2000.

The country's population will enter to the old stage at one decade earlier according to the measure of proportion of children and aging index than that of measured with proportion of aged and the median age. At the half of this century, young-old ratio will be unity, and then there is a tendency to outnumber of the aged to the children up to the projection period 2071. At the end of 21st century, half of the population will be aged above forty (Figure 1). This scenario confirms that Bangladesh will be an aged nation within this century with relatively poor socioeconomic condition as country's economic growth rate is not hopeful.

\section{Level of Dependency}

The demographic aging process can be examined by studying structural change in its population age distribution. The working force and dependency ratio are related with population aging, and these can be considered as an alternative view of population aging. Age-based dependency is the simplest analysis of the economic effects of population aging, and the notion of this measure is that people of some ages produce less than they consume and are dependent on the rest of the society for their support. This crude measure ignores the question of how resources are transformed from working adult to dependent children and elderly and is based on the assumption that output is produced solely by the labour of working age adults, with no additional factors of production such as capital [13].
Some social scientists and political persons have been concerned about the growing number and percentage of the population that is dependent on people of age for supports. The idea is that one part of the population works, primarily those between 20 and 65, and supports the proportions of the two groups get out of balance, that is, if there were too many dependent people in relation to the size of the working population, then it might become a burden on those who are still employed, and the prosperity of the entire population might suffer [14].

There is increasing and decreasing pattern of old and young dependency that has been observed, respectively, over the projected period, but, from the middle of this century, the rising rate of old dependency will be faster than the falling rate of young dependency and ultimately old dependency will cross the young dependency level. Bangladesh is gaining demographic dividend from its aging process, and this enjoyment of earning will continue over the first three decades of this century as young dependency will be decreasing faster than the increasing old dependency causing the decreasing patterns of total dependency (Figure 2). Therefore, it is clear that future Bangladesh will face the problem of demographic burden.

\section{Future Trajectory in the Elderly Support Capacity}

According to the potential support ratio (PSR), there are approximately 9 persons available in active population to support per elderly people though the actual economic support depends on the employment opportunity of economically active population. Due to the comparatively large number of active population, there is no visible support facility shortage now in term of PSR.

Over the current century, projected period, this support ratio shows a clear decreasing trend where, at the 3 rd quarter 


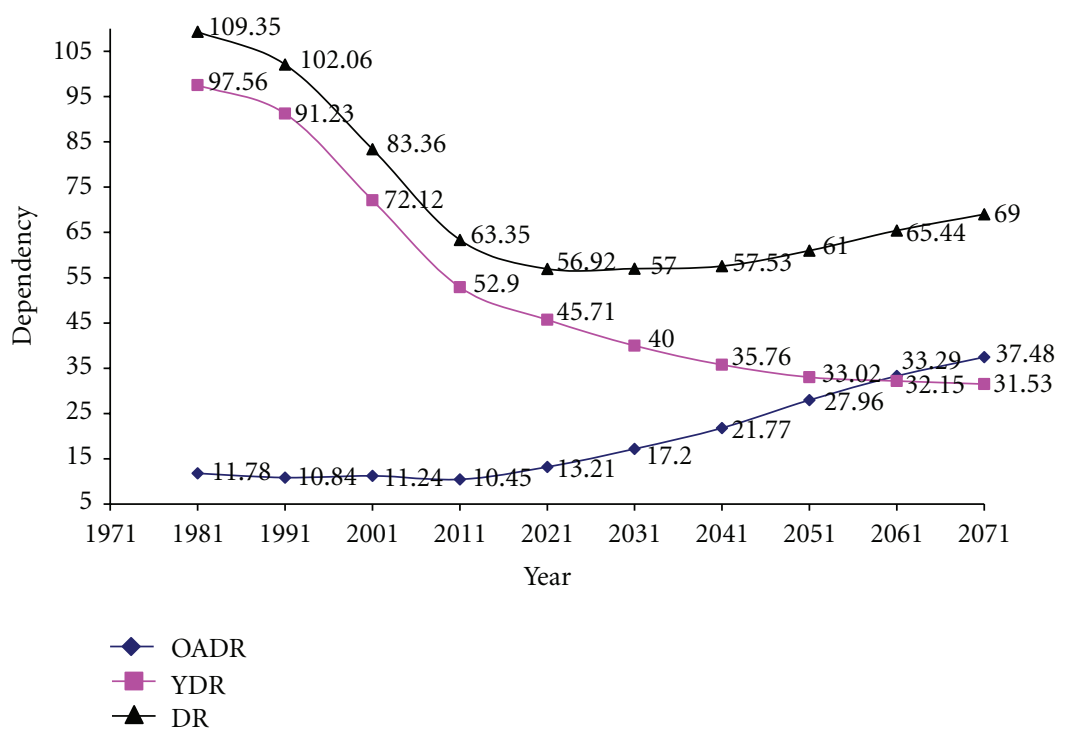

FIgURE 2: Dependency of Bangladesh population, 1981-2071.

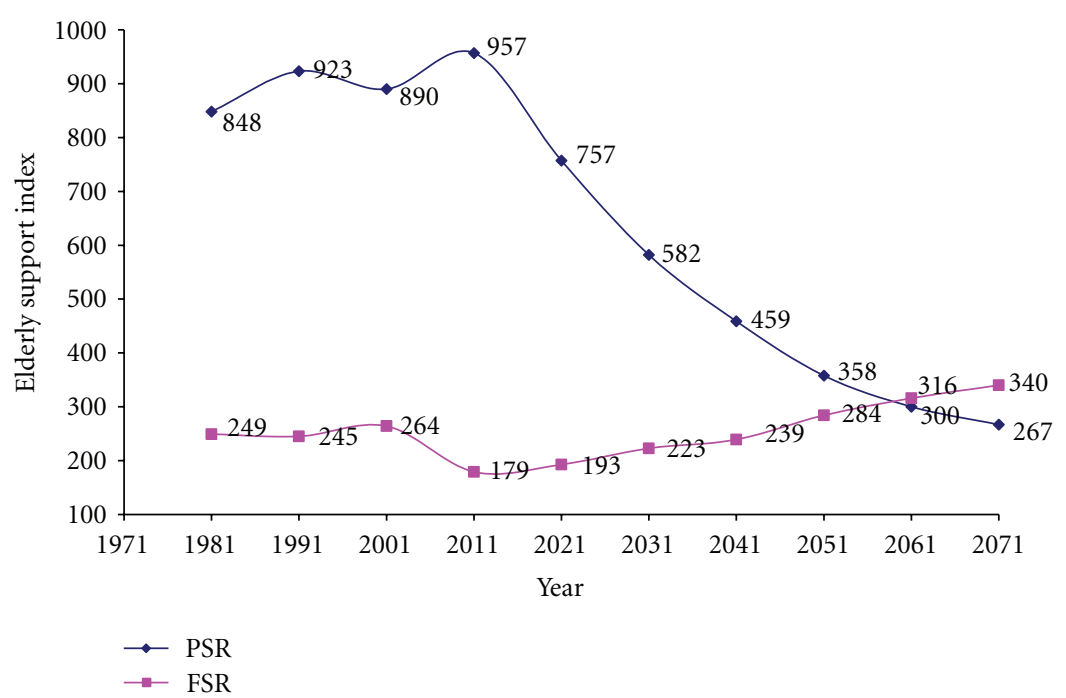

FIGURE 3: Elderly support ratio of Bangladesh population, 1981-2071.

of this century, 3 persons will be available in the economically active population to support per elderly person (Figure 3 ). This may be due to relatively small birth cohort will enter into the work force and large cohort will enter into the oldage group.

Generally, females are considered as better for care giving supports to the elderly. In a family or community, women aged 50-59, who are able to provide support to elderly, are more conscious about the elderly care. In a 1992 survey by the Families and Work Institute of USA, it was found that, on an average, women spend more time than men caring for elders. Indeed, the time spent by women to meet these responsibilities is equivalent to a half-time job. Of the elderly who receive care, 92 percent of them receive it from family members and 8 percent receive it from friends and neighbours in USA [15]. Familial support ratio (FSR) is another measure of elderly support system. In 2001, approximately 264 females (age 50-59) are able to care 100 elderly persons. This support potentiality shows an increasing trend over the time period 1981-2071 with a very slow pace. This may be due to the reducing rate of maternal mortality (MMR) of this country. The future elderly of Bangladesh seem to be lucky regarding support potentiality with the measure of FSR.

Elderly sex ratio is an indirect measure of support system of the family as it gives a rough idea about having spouse or not. Generally, Bangladeshi elderly women are less likely to have spouse than their male counterpart though the number of women elderly is lower than that of male. Sex ratio of the elderly is 124 male per 100 women at 2001, but it will fall dramatically at 2011 and then a steady declining trend has been observed according to the projected data 


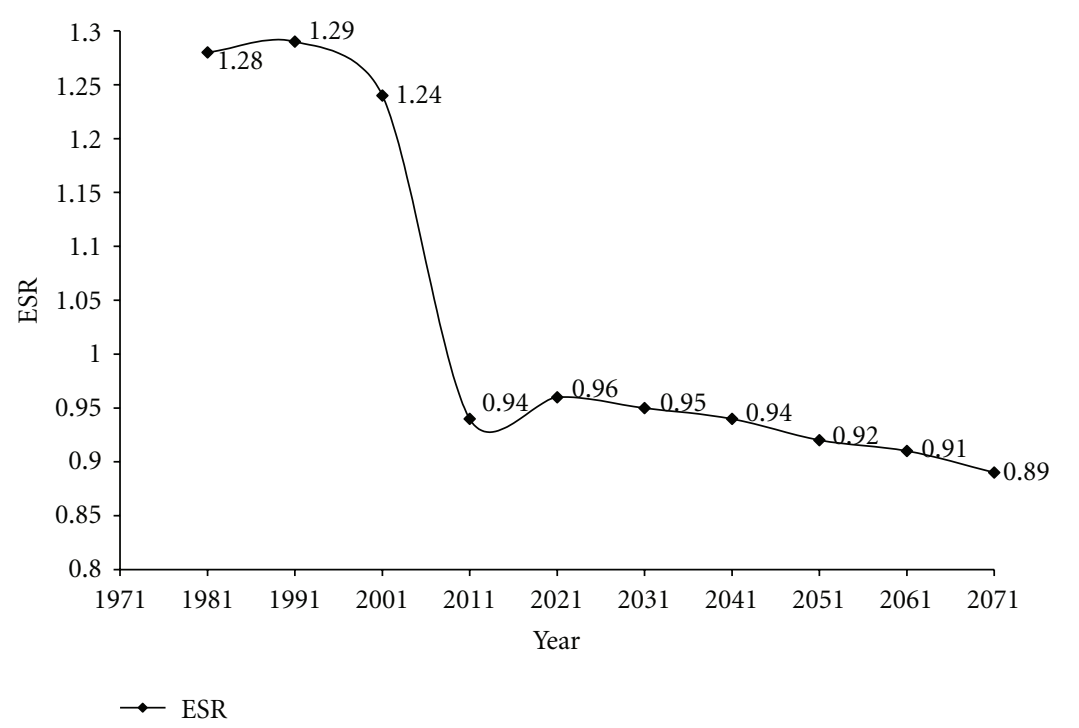

FIgURE 4: Elderly sex ratio of Bangladesh population, 1981-2071.

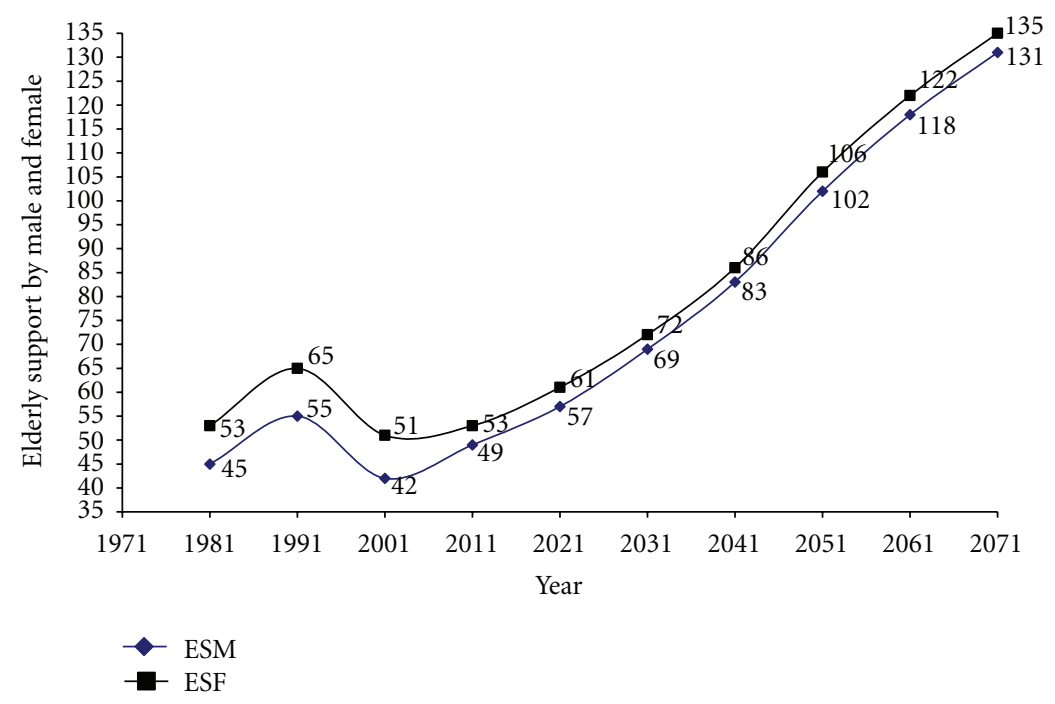

FIGURE 5: Elderly support ratio by male and female of Bangladesh population, 1981-2071.

(Figure 4). It indicates more female elderly without spouse. Since female elderly is more vulnerable in terms of socioeconomic condition of the country, hence Bangladesh female elderly will have to face miserable situation in the future.

Again, elderly support ratio by male and by female have been calculated with Goyal's idea to study the elderly support capacity. The support ratios by males and by females were 42 and 51, respectively, in 2001 that is per hundred men and women of aged 35-59 have to provide support to 42 and 51 elderly, respectively. The burden of supporting elderly by male and female of that age will be increasing in the projected period, and, at the middle of this century, each male and female, aged 35-59, will have to give support one elderly on an average. The rising trend of need for supporting elderly is clear over the projected period. The potential support of the elderly by female is relatively high for all the years under study (Figure 5).
The Ministry of Social Welfare of Bangladesh has finalized the National Policy for the elderly people [16]. These policies include their social security, health care services, financial security, national awareness program, coordination between older persons and new generation, but there is not enough strategy for caring support for the elderly in future. The future support capacity for the elderly in Bangladesh has been focused on in this study according to the demographic point of view. Widowed elderly especially females feel more loneliness than those of having spouse. A wide age gap between bridegroom and bride exists in the society. Therefore, a policy should be taken to reduce the age gap between them in future. The nongovernment organization (NGO) in Bangladesh is doing well in its different programs for children and mothers, but it has not visible initiatives for the betterment of the elderly support systems. It will be better to run the elderly support facility jointly by the government 
and nongovernment organizations. Due to the modern health facilities and increase in health awareness, the life expectancy is rising day by day in the country. A national committee should be formed to revise the retirement age in every 20 years based on demographic information especially life expectancy and healthy life expectancy. A future plan should be taken to introduce geriatric wards in the existing hospitals. It should be ensured elderly issues in the national education system especially introducing modern geriatric syllabus in the medical education. It will be better to involve the elderly in the faith-based institutions and voluntary programs in future. Briefly, it can be said that the support in old age can be achieved in a variety of ways. The family support, public and private social assistance, mutual benefit, social insurance, personal savings, occupational pensions are some of the programs to be taken for future. More gerontological research and awareness are important for the society to develop programs and services that would be culture-sensitive and effective to address the aging issues.

\section{Conclusion}

This study considers the future journey of the elderly support capacity with economic and caring aspects. From the demographic point of view, elderly persons will face the problem of financial and nursing support except for the measures with familial support ratio measures. This familial support for caring about the elderly may not be available due to lack of economic solvency of the society. The women empowerment of the country is increasing, and their participation in the working sector is rising day by day. The ongoing process of forming nuclear family will add more pressure on the elderly support system. These types of social changing along with the economic hardship will be serious threat to the elderly support system of Bangladesh. It is the high time to think about it and to take long-term sustainable aging policies to face the future problem. This policy may be taken phase by phase with the inclusion of this issue in the country's fiveyear planning.

\section{References}

[1] United Nations (UN), World Population Aging 1950-2050, Population Division, DESA, UN, 2007.

[2] R. S. Goyal, "Implications of demographic and socioeconomic transition for elderly: an illustration from India," International Journal of Anthropology, vol. 15, no. 1-2, pp. 19-31, 2000.

[3] J. S. Siegel, "On the demography of aging," Demography, vol. 17, no. 4, pp. 345-364, 1980.

[4] R. Tabbarah, Demographic Trends of Aging in the Arab Countries, United Nations Economic and Social Commission for Western Asia, Beirut, Lebanon, 2002.

[5] J. L. Waite, "The demographic faces of the elderly," Population Development Review, vol. 30, supplement, pp. 3-16, 2004.

[6] M. Cain, "The consequences of reproductive failure: dependence, mobility and mortality among the elderly of rural South Asia," Population Studies, vol. 40, no. 3, pp. 375-388, 1986.
[7] Rahman, Atiqur, and A. S. M. Banglapedia, Aging. National Encyclopaedia of Bangladesh, Asiatic Society of Bangladesh, 2006.

[8] H. T. A. Khan and G. W. Leeson, "The demography of aging in Bangladesh: a scenario analysis of the consequences," Hallym International Journal of Aging, vol. 8, no. 1, pp. 1-21, 2006.

[9] D. C. Nath and M. N. Islam, "New indices: an application of measuring the aging process of some Asian countries with special reference to Bangladesh," Journal of Population Ageing, vol. 2, no. 1-2, pp. 23-39, 2009.

[10] M. N. Islam, D. C. Nath et al., "Measuring Bangladesh's aging process: past and future," in Population, Gender and Health in India: Methods, Process and Policies, K. S. James et al., Ed., pp. 153-165, Academic Foundation, New Delhi, India, 2010.

[11] Bangladesh Bureau of Statistics (BBS), "Population census 2001," National Report (Provisional), Ministry of Planning, Dhaka, Bangladesh, 2003.

[12] U. S. Census Bureau, "International Data Base (IDB)," 2008, http://www.census.gov/ipc/www/idb .

[13] D. N. Weil, "Population growth, dependency, and consumption," American Economic Review, vol. 89, no. 2, pp. 251-255, 1999.

[14] H. Roy and C. Russel, The Encyclopaedia of Aging and the Elderly, Medrounds, 2006.

[15] I. I. Smith and G. P. Legal, Healthcare Ethics for the Elderly, Taylor \& Francis, Boca Raton, Fla, USA, 1996.

[16] Government of Bangladesh (GOB), Poverty Alleviation, Human Resource Development and Ministry of Social Welfare, Ministry of Social Welfare, Dhaka, Bangladesh, 2007. 


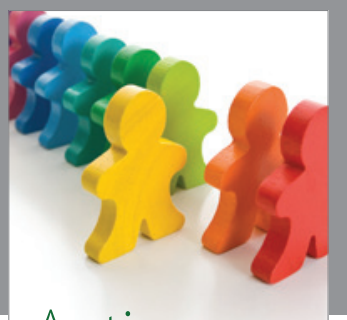

Autism

Research and Treatment
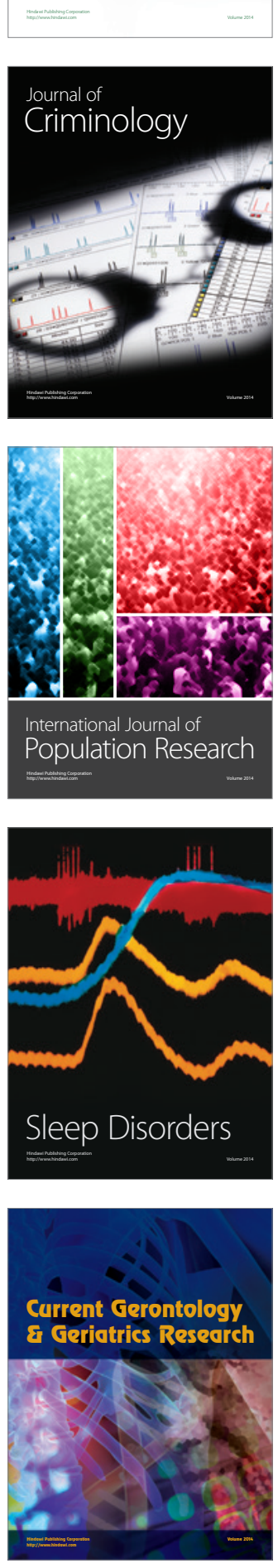
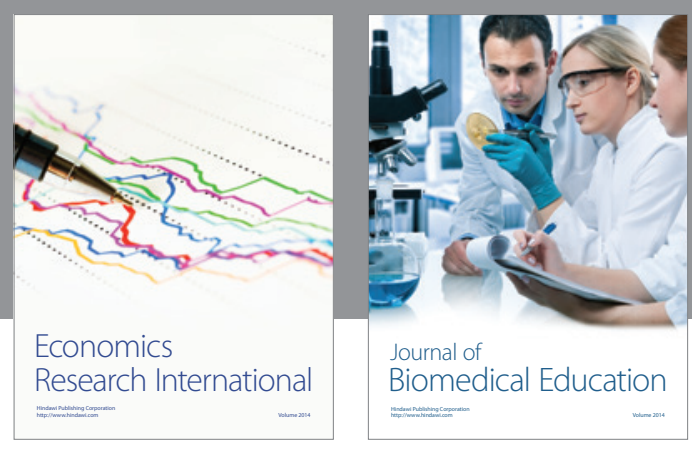

Journal of

Biomedical Education

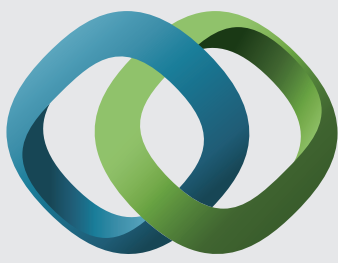

\section{Hindawi}

Submit your manuscripts at

http://www.hindawi.com
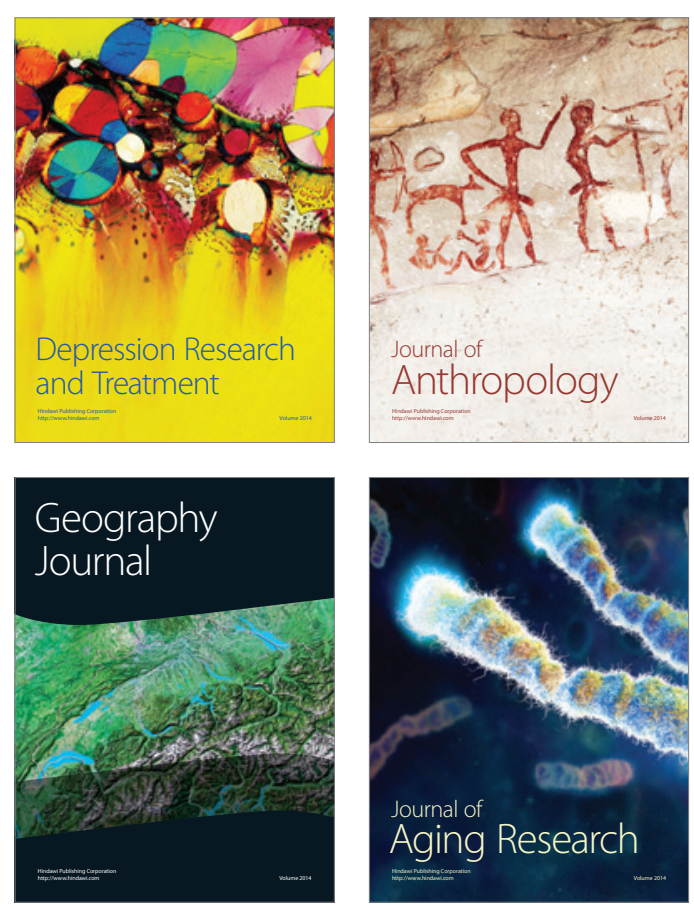

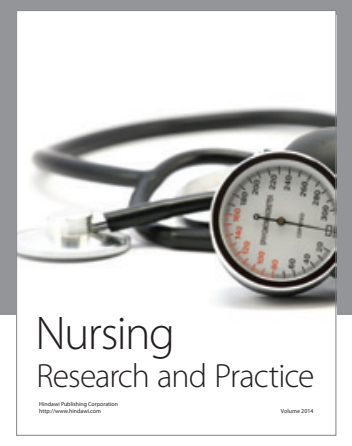

Nursing

Research and Practice

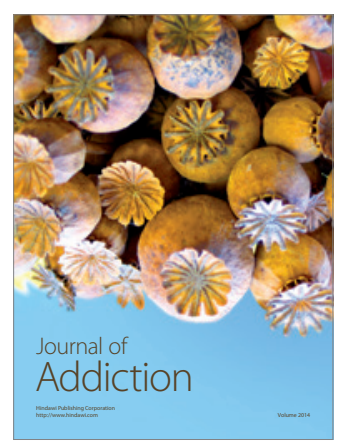

Child Development

Research

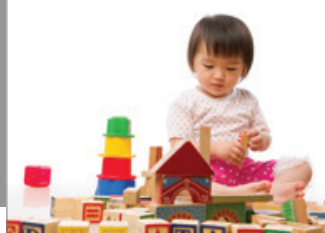

迥
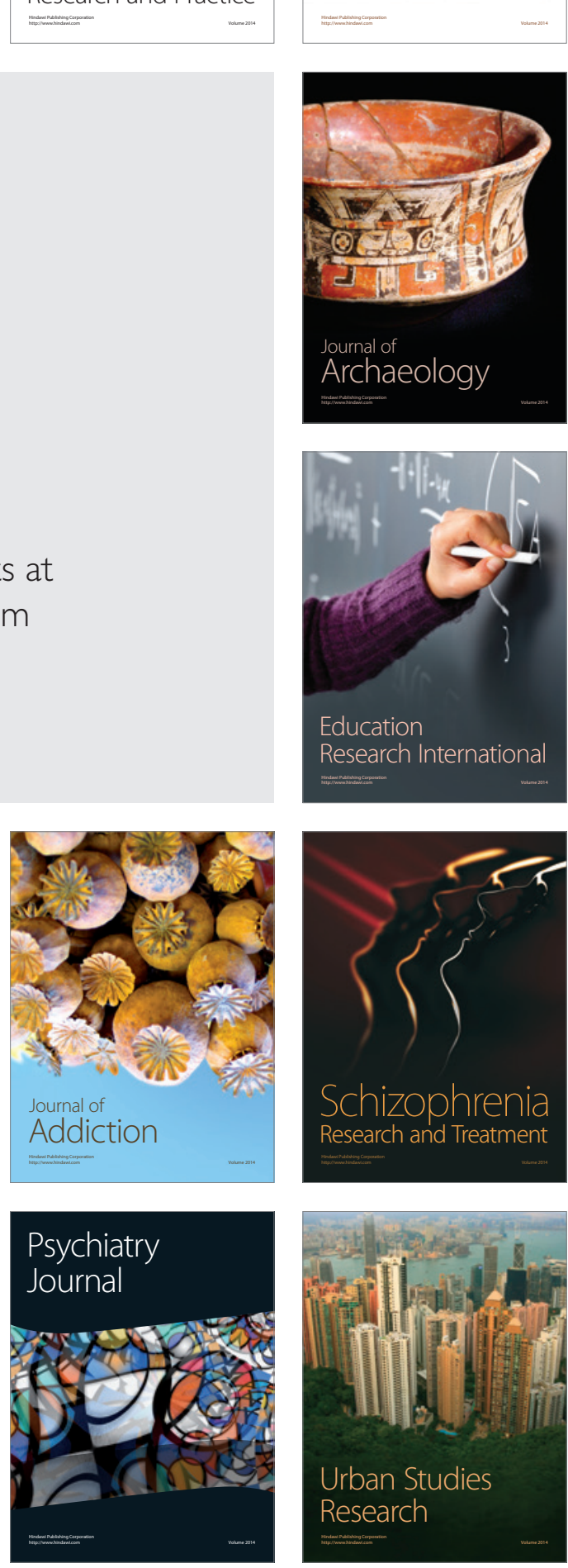